\title{
The Doctor Who Cried: A Qualitative Study About the Doctor's Vulnerability
}

\author{
Kirsti Malterud, $M D, P b D^{1,2}$ \\ Hanne Hollnagel, MD, $P b D^{1}$ \\ ${ }^{1}$ Research Unit and Department of General \\ Practice, University of Copenhagen, Panum \\ Institute, Denmark \\ ${ }^{2}$ Section for General Practice, Department \\ of Public Health and Primary Health Care, \\ University of Bergen, Norway
}

\begin{abstract}
PURPOSE We wanted to explore those clinical events when doctors had exposed their vulnerability toward patients in a potentially beneficial way.

METHODS We undertook a qualitative study based on memory work, a structured approach to transform memories into written texts. Study participants were 9 members of a research group who had known each other a couple of years. They were asked in advance to recall a clinical event during which vulnerability was perceived and exposed in a way appreciated positively by the patient. During a group meeting, participants wrote their individual memory stories recalling these events, and the subsequent group discussion was audiotaped, transcribed, and analyzed using a phenomenological approach, applying specific linguistic cues to reveal points of special interest. The main outcome measure was the vulnerability expressed by practitioners.
\end{abstract}

RESULTS Vulnerability had been experienced and exposed by the participants on several occasions during which the patients had confirmed its potentially beneficial effect. All reported events could be interpreted as different ways of personal disclosure toward the patient. We identified two kinds of disclosure: spontaneously appearing emotions and considered sharing of experiences.

CONCLUSION A spontaneous exposure of emotions from the doctor may help the patient, and sharing personal experiences may lead to constructive interaction. We need to know more about when and how personal disclosure and other aspects of vulnerability exposed by the doctor are experienced as beneficial by the patient.

Ann Fam Med 2005;3:348-352. DOI: 10.1370/afm.314.

\section{INTRODUCTION}

W e never forget the dominant lesson from medical school: doctors are omnipotent, detached, and impersonal. ${ }^{1,2}$ Yet, as general practitioners such as Novack et $\mathrm{al}^{3}$ and $\mathrm{Zinn}^{4}$ have taught us, medical work is unavoidably laded with emotion and enhanced by personal awareness. A reflexive practitioner is needed for skilled reading of the patient's story. ${ }^{5}$ The emotional pressures and high job stresses that doctors face are risk factors for burnout. ${ }^{1,6,7}$ Patients expect their practitioner to keep up-to-date on the latest scientific evidence, but they also want a doctor who cares. ${ }^{8}$ Mutual trust in the relationship between doctor and patient is grounded on the presumption that relevant information and emotions should be shared. ${ }^{9}$ What is supposed to be relevant or, on the contrary, regarded as a violation of boundaries is a matter of debate. ${ }^{10,11}$ How then can doctors use their emotions and personal experiences in the best service of their patients? We decided to take the potential strength of vulnerability as our point of departure by exploring clinical events during which vulnerability had been perceived and exposed in a way appreciated by the patient.

\section{METHODS}

This exploratory qualitative study was based on memory work about clinical events and a subsequent group discussion. Memory work is a research 
method developed by the German sociologist Haug ${ }^{12}$ from theories about identity formation and social structure, cultural norms, and human relationships. The method is a structured approach to transform memories into texts, which can then be studied more closely. Writing memory stories creates distance and can provide space for reflection, which is better suited than oral storytelling for developing material for analysis. The issue of distance is further strengthened by writing in the third person. After writing, the group takes the stories, or a selection of them, as a point of departure for an analytic discussion. Metaphors and contradictions in the text are used to reveal points of special interest. Differences and similarities are explored while focusing on commonalities across stories. ${ }^{12}$

The memory work was done with our research group, consisting of 2 men and 7 women (including ourselves). Seven participants were general practitioners or psychologists, aged between 41 and 61 years. Two participants were sociologists, aged between 36 and 42 years; these 2 participants had no clinical experience but had some patient experience. The group members knew each other from previous meetings about research questions. The participants were asked in advance to recall a clinical event where the doctor's vulnerability had been perceived and exposed in a manner that the patient had appreciated as positive. Participants were given 20 minutes to write their individual memory story, not to exceed 1 page of paper. Appendix 1 is a typical example.

The 9 stories were then collected and read aloud. The group gave each story a name indicating the content (Table 1). Based on discussions about differences and similarities, we concentrated the subsequent analysis on 3 stories ( $\mathrm{A}, \mathrm{E}$, and $\mathrm{H}$ ) that we agreed represented some essential dimensions of vulnerability. During the discussion, which was audiotaped and transcribed, we examined each story closely, noting linguistic cues that indicate issues about social structure, cultural norms, and human relationships. Elements from remaining 7 stories were also used.

Together the authors performed qualitative analysis based on the 9 written memory stories and the

\section{Table 1. Memory Stories}

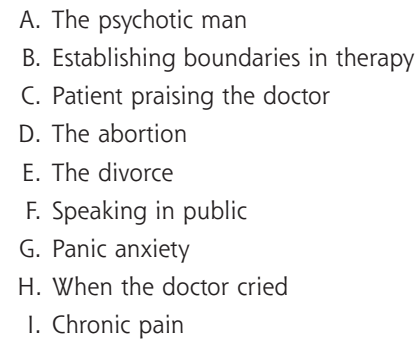

\section{Appendix 1. The Doctor Who Cried}

"The patient visits because her husband is seriously ill with metastasizing cancer. The doctor has known her (but not him) for years and followed the course of disease. The patient has 2 small children, and says that it is difficult to tell the children how ill their father is. Now they have received the message that nothing more can be done and that he will die within a few days.

Tears burst into the eyes of the doctor when the patient tells this. She must swallow and gets Kleenex. The patient does not cry. Then the doctor writes another sick leave certificate to her. The patient has previously been sick-listed several times in this period. Some days later, the husband dies.

Later on, the patient describes this event publicly. She says it had meant a lot for her that the doctor became touched."

transcript from the group discussion. The material we identified about aspects of vulnerability perceived by doctors was used for systematic text condensation according to the principles of Giorgi's phenomenological analysis ${ }^{13}$ and modified by Malterud. ${ }^{14}$ We concentrated on the position of the doctors also in the stories from the sociologists. The analysis followed these steps: (1) reading all the material to obtain an overall impression, and bracketing preconceptions; $(2)$ identifying units of meaning representing different aspects of vulnerability, and coding for these aspects $;$ (3) condensing and abstracting the meaning within each of the coded groups; and (4) summarizing the contents of each code group to generalize descriptions and concepts reflecting perceived important experiences of vulnerability. We also condensed the essence of the experience in each story (as shown in the short versions below).

The study was approved by the regional committee for medical research ethics, Bergen, Norway.

\section{RESULTS}

\section{The 9 Memory Stories in Short}

The psychotic man (A) was forcibly admitted to a mental hospital. Because the ride to the hospital was long, he was given a heavy dose of tranquilizer before departure. Later, the patient told about the hospital's harsh criticism of the doctor regarding the heavy medication but said that he forgave the doctor because she was young and inexperienced. In establishing boundaries (B), a patient drowned her therapist in e-mails and mobile phone text messages; the therapist felt so invaded, she desperately interrupted the contact. When therapy resumed 1 year later, the patient said she had felt discarded but still learned something about how other people might experience her. Another patient praised her doctor (C), who had given good support during a difficult period. The doctor felt embarrassed and was not immediately able to receive the praise from the patient. In the story about the abortion (D), a medical student opened up by expressing his fear and distaste during the operation in 
a way that gave the patient the strength to endure and get ready. The divorce story $(\mathrm{E})$ deals with a patient who was upset because she feared that her children would be staying with her ex-husband in the future. The doctor revealed that she had been in a similar situation. In the story about speaking in public $(\mathrm{F})$, the therapist admits to the patient, who does not dare to attempt public speaking, that he has the same problem. Panic anxiety $(\mathrm{G})$ is about a doctor seeing a patient who was suffering from severe panic attacks. An important positive change appeared after the doctor described his own similar symptoms in great detail. The memory story about the doctor who cried $(\mathrm{H})$ as an expression of empathy is fully described in Appendix 1. Chronic pain (I) describes an encounter with a patient who complained about her symptoms but felt that she had not been heard by her doctor. Afterward, she returned and claimed that she would not accept such attitudes, because her symptoms were real. The doctor apologized and was then able to acknowledge the patient's symptoms.

Below, we present the analysis of positively perceived vulnerability based on the memory stories and the group discussion.

\section{Disclosure of Emotions or Experiences}

The 9 events reported were quite different; yet, their common denominator was that some kind of vulnerability that had been experienced and exposed by the practitioners. We also heard substantial comments about how the patient had appreciated what happened. In several stories, vulnerability resulted in a personal or emotional disclosure. Such disclosure could take place as spontaneously appearing emotions or as considered sharing of experiences. These 2 patterns, leading us to hypothesize disclosure to be an important aspect of a positive expression of vulnerability, are further elaborated below.

\section{A Spontaneous Human Touch}

Several memory stories dealt with clinical events during which doctors renounced their usual professional control and allowed emotions to slip through during a patient encounter. The act was not planned; it simply happened, such as in the consultation when the doctor started to cry.

The stories confront the cultural expectation that doctors usually do not reveal themselves when they are emotionally touched. Emotional reactions nevertheless became visible through bodily symptoms, such as red flushes on the skin of the throat or face, betraying the apparently controlled doctor. The doctor herself may have perceived these signs as palpitations. A feeling of professional inadequacy could have added to perceived vulnerability. On the other hand, even successful actions were not always easy to handle either.
Summary of memory story C. The doctor was praised by the grateful patient who felt that she had been acknowledged and treated as an equal by her doctor. The doctor was embarrassed and said that this was certainly his job. The patient, whose compliments had been rejected, challenged the doctor, saying that it was not easy to praise him. The doctor then admitted that accepting praise was one of his weak sides.

To the patient this admission revealed the doctor's vulnerability and gave her the feeling that they had something in common. Other stories, such as the one about the patient in chronic pain accusing the doctor of not listening adequately, illustrate the positive impact of the doctor honestly and spontaneously admitting that the patient was right.

The group identified several expressions from the stories as pointing to important interaction issues. We noted the simple language describing how the doctor spontaneously embodied the patient's emotions without hiding the feelings evoked. The stories show how medical events concerning the eternal questions of death and life may activate the universal vulnerability shared by all human beings when reminded of being mortal. We also noted the disempowerment of the doctor, which can be triggered by the lack of adequate actions that can be taken within the traditional framework of medical practice.

\section{Thoroughly Considered Disclosures}

Compared with the spontaneous outbursts of emotions described above, there were also memory stories about thoroughly considered interventions in which practitioners shared their own demanding personal experiences with their patients. The doctors seemed to check their objections to telling about their nervousness related to public speaking, their anxiety disorder, or their divorce.

Summary of memory story E. A patient, whom the doctor had seen a couple of times, sought care during her divorce proceedings. She was very upset that her children would probably be living with their father in the future and felt that her role as a mother who abandons her children was intolerable. The doctor very briefly admitted that she herself was in a similar situation, that her children were living with her ex-husband. The doctor afterward observed a constructive interaction in the consultation.

In this case, the doctor spoke about a past vulnerability, not a present situation. By appearing as a confident survivor of such a complicated problem, she could represent a safe platform and offer hope for the patient's future.

After disclosure, in these stories, the agenda was handed back to the patient by, for example, inviting the patient to ask further questions. Reclosing the disclosure was presented as an option. Sharing experiences with the patient may evolve from the doctor's 
identification with the patient and activated by an exceptional feeling of similarity as human beings. We noticed expressions from the memory texts, such as "on her own age," referring to identification that appears to activate the "now I will tell you" exchange.

Summary of memory story G. A patient expressed disappointment toward her doctor, feeling that her intense panic attacks were not being taken seriously. The doctor, who had herself experienced a long period of panic attacks, then chose to describe in great detail her first attack and the consequences for her life situation. The patient told her that this description fit well with her own symptoms. She perceived a new level of insight and empathy from the doctor compared with her doctor's response in previous consultations.

The patient's response to disclosure can clarify what was the right thing to do in the individual case, such as the doctor who ended the relationship with a patient who behaved importunately toward her. Later on, the patient admitted that this apparently dismissive action had been a notable event for her, although at the time she had projected her bad feelings to the doctor.

The language of these memory stories indicates strategies that are somehow calculated, yet they do not fall within the everyday course of clinical interaction. Transcending usual procedures was found in stories in which the doctor considered the issue of disclosure and hesitated for a moment, as if balancing the potential effects of the expression. Several small signs of justification in the stories also point to breaking the implicit rules that regulate what doctors are supposed to talk about.

\section{DISCUSSION}

\section{Memory Stories About Lived Stories?}

Narrative truths are provisional, uncertain, and derived from narrators whose standpoints are always situated, particular, and uncertain, but open to comparison and reinterpretation. ${ }^{15}$ This study group was distinguished by trust and confidence, which enhanced exposure of intimate issues. We found that memory work had added benefits compared with reflective writing — a method for teaching medical students empathy. ${ }^{5}$ The third person account of the written format, as well as cues for subsequent discussion, allowed us to recognize issues beyond the most obvious. We all agreed with the paradox of being able to discuss personal issues more closely when the format was deliberately distanced. This format allowed others to provide more vivid comments, because, unlike a biographical first-person account, the author was not personally as invested in the story.

The authors also participated in writing as well as in the group discussion, which is part of the process of memory work. There are no strong boundaries between researchers and informants, because the study deals with the commonalities of human experiences. ${ }^{12}$ Writing the stories in private and asking participants to find a story in advance, however, increased the chance of approaching different themes.

Qualitative studies do not claim generalizability on a population level. External validity of the findings is related to the potential for gaining new understanding from the descriptions and concepts developed. Although this exploratory study was based on a limited sample, the descriptions and concepts identified from our data clearly indicated a hypothesis that personal and emotional disclosure under certain conditions constitutes a positive aspect of vulnerability. These patterns were sufficiently consistent across the material to deserve attention for further research in which emphasis should be put upon the preconditions for positive patient experience.

\section{Potentials and Pitfalls of Exposing Personal Issues}

Practitioners' vulnerability can be related to personal as well as professional issues. Our data invite us to concentrate on the former, although the latter, exposing perceived inadequacy, deserves attention in further studies. Our stories about thoroughly considered disclosure can supplement Candib's findings, ${ }_{1}^{16}$ while our descriptions of practitioners' spontaneous emotional disclosure to our knowledge are unique. We found no indications that disclosure had happened because the practitioner consciously intended to challenge prevailing norms.

Beach and coworkers ${ }^{17}$ found that doctor self-disclosure occurred in $17 \%$ of primary care visits. Selfdisclosure statements included reassurance, counseling, rapport building and casual, intimate, and extended narratives. ${ }^{18}$ Self-disclosure is described as a complex communicative behavior that is not necessarily good or bad. Yet, among the 195 events studied, intimate or extended disclosures, which may be thought of as self-preoccupied or a misuse of the patient's time, were rare. ${ }^{18}$

Balint ${ }^{19}$ said that the most frequently used drug in general practice was the doctor. Yet, no pharmacology of this important drug exists. There is no guidance as to the dosage to which the doctor should prescribe himself or the possible hazards or the undesirable side-effects of the drug. ${ }^{19}$ We have focused on events where an exceptionally high dosage was perceived to give a good outcome. The benefit was not a finding, but an inclusion criterion (although a proxy one). We do not know whether these events actually benefited the patients, except for the stories related by those of us who were not therapists. These group members also served to validate the outcome of the therapists' stories. The painful act of disclosing professional experiences in which conventional rules for clinical interaction may be broken 
requires justification - a dimension obviously mingled into the ways patients' responses are related by the storytellers. We checked these parts of the text to find that they mostly referred to events interpreted as credible confirmations of patient benefit.

Riordan described identity management strategies applied by gay and lesbian practitioners to achieve the proper balance between passing and disclosure in the consultation. ${ }^{20}$ Doctors who constantly hide essential identity issues, whether sexual identity or just emotions, endure burdens that in the long run may sap their energy and lead to a detached style. Although disclosure may be a high-risk strategy for the doctor, sharing may offer personal relief as well as contribute to reducing the patient's perception of stigma. ${ }^{16}$

Our study illuminates how vulnerability is a human quality, and the doctor does not always have the option of balancing the pros and cons of expressing emotions. In his Holocaust study, Vetlesen argues for the indispensable role of emotion, especially the faculty of empathy, for moral perception and judgment. ${ }^{21}$ Moral capacity, elaborated within the social environment of a small-scale setting, prevents the dissociation and abstraction necessary to renounce the suffering of others. Hunter reminds us that moral knowing is not separable from clinical judgment. ${ }^{15}$ Translated to the clinical context, the doctor's perception and exposure of emotions are essential to understand patients and their problems and to recognize the distinctive relational character of general practice.

We discussed the limits of inappropriate disclosure at the interface of considered and spontaneous sharing. Candib points to the issue of power when sharing occurs in a setting between unequal parties. ${ }^{16}$ Our findings do not justify an unconditional reciprocity of intimacy. What goes on in the physician's office is supposed to benefit the patient, not liberate or heal the doctor. Disclosure that is self-protective or that invites the patient to become the doctor's therapist should be abandoned. ${ }^{22}$ The practitioner's training should therefore include reflexivity, not only about the cognitive dimensions of thoughtful sharing, but also about the spontaneous emotions of the doctor. We need to learn more about how responsible and responsive emotional knowing can be enacted, ${ }^{23}$ acknowledging our own vulnerability when recognizing the patient's needs.

To read or post commentaries in response to this article, see it online at http://www.annfammed.org/cgi/content/full/3/4/348.

Key words: Family practice; qualitative research; professional role; disclosure; vulnerability; memory work

Submitted August 29, 2004; submitted, revised, January 7, 2004; accepted January 11, 2005.

Funding support: Eckbo's legacies provided funding for this study.
Acknowledgments: We thank members of the research group, "Vulnerability as a strength-how can experiences of disempowerment become health resources," for participating in the memory work and contributing in the group analysis from which this article was developed.

\section{References}

1. West L. Doctors on the Edge. General Practitioners, Health and Learning in the Inner-City. London: Free Association Books; 2001.

2. Sinclair S. Making Doctors. An Institutional Apprenticeship. Oxford: Berg; 1997.

3. Novack DH, Suchman AL, Clark W, Epstein RM, Najberg E, Kaplan C. Calibrating the physician. Personal awareness and effective patient care. JAMA. 1997;278:502-509.

4. Zinn WM. Doctors have feelings too. JAMA. 1988;259:3296-3298.

5. DasGupta $S$, Charon R. Personal illness narratives: using reflective writing to teach empathy. Acad Med. 2004;79:351-356.

6. Tyssen R, Vaglum P, Gronvold NT, Ekeberg O. The impact of job stress and working conditions on mental health problems among junior house officers. A nationwide Norwegian prospective cohort study. Med Educ. 2000;34:374-384.

7. Felton JS. Burnout as a clinical entity-its importance in health care workers. Occup Med (Lond). 1998;48:237-250.

8. Williams S, Weinman J, Dale J. Doctor-patient communication and patient satisfaction: a review. Fam Pract. 1998;15:480-492.

9. Katz J. The Silent World of Doctor and Patient. 2nd ed. Baltimore, MD: Johns Hopkins University Press; 2002.

10. Farber NJ, Novack DH, Silverstein J, Davis EB, Weiner J, Boyer EG. Physicians' experiences with patients who transgress boundaries. J Gen Intern Med. 2000; 15:770-775.

11. Farber NJ, Novack DH, O'Brien MK. Love, boundaries, and the patient-physician relationship. Arch Intern Med. 1997;157:2291-2294.

12. Haug F. Female Sexualization : A Collective Work of Memory. London: Verso; 1987.

13. Giorgi A, ed. Sketch of a psychological phenomenological method. In: Phenomenology and Psychological Research. Pittsburgh, Pa: Duquesne University Press; 1885:8-22.

14. Malterud K. Qualitative research: standards, challenges, and guidelines. Lancet. 2001;358:483-488.

15. Hunter KM. Narrative, literature, and the clinical exercise of practical reason. J Med Philos. 1996;21:303-320.

16. Candib LM. What doctors tell about themselves to patients: implications for intimacy and reciprocity in the relationship. Fam Med. 1987; 19:23-30.

17. Beach MC, Roter D, Rubin H, Frankel R, Levinson W, Ford DE. Is physician self-disclosure related to patient evaluation of office visits? J Gen Intern Med. 2004;19:905-910.

18. Beach MC, Roter D, Larson S, Levinson W, Ford DE, Frankel R. What do physicians tell patients about themselves? A qualitative analysis of physician self-disclosure. J Gen Intern Med. 2004;19:911-916.

19. Balint M. The Doctor, his Patient and the Illness. London: Pitman Medical; 1971.

20. Riordan DC. Interaction strategies of lesbian, gay, and bisexual healthcare practitioners in the clinical examination of patients: qualitative study. BMJ. 2004;328:1227-1229.

21. Vetlesen A-J. Perception, empathy, and judgment. Constellations. 1994:1 427-430.

22. Nisselle P. Is self-disclosure a boundary violation? J Gen Intern Med. 2004; 19:984.

23. Malterud K, Candib L, Code L. Responsible and responsive knowing in medical diagnosis: the medical gaze revisited. Nora. 2004;12:8-19. 